\title{
The interoperability force in the ERP field
}

Andres Boza ${ }^{1}$, Llanos Cuenca ${ }^{1}$, Raul Poler ${ }^{1}$, Zenon Michaelides ${ }^{2}$

${ }^{1}$ Research Centre on Production Management and Engineering (CIGIP), Universitat Politècnica de València. Camino de Vera S/N, 46022, Valencia, (SPAIN).

${ }^{2}$ Management School, University of Liverpool, Liverpool, (UK)

Tel.:+34 963877007 Fax: +34 963877689

aboza@cigip.upv.es, z.m.michaelides@liverpool.ac.uk

Corresponding Author: Andrés Boza 
The interoperability force in the ERP field

ERP systems participate in interoperability projects and this participation sometimes leads to new proposals for the ERP field. The aim of this paper is to identify the role that interoperability plays in the evolution of ERP systems. To go about this, ERP systems have been firstly indentified within interoperability frameworks. Secondly, the initiatives in the ERP field driven by interoperability requirements have been identified from two perspectives: technological and business. The ERP field is evolving from classical ERP as information system integrators to a new generation of fully interoperable ERP. Interoperability is changing the way of running business, and ERP systems are changing to adapt to the current stream of interoperability.

Keywords: ERP, Interoperability, Information Systems, Enterprise Systems, Enterprise Applications

\section{Introduction}

Enterprise Resource Planning (ERP) systems are information systems (IS) designed to integrate and optimise business processes and transactions in a corporation by embracing different areas such as manufacturing, human resources, finance/accounting, sales, etc. ERP are universally accepted by the industry as a practical solution to achieve integrated enterprise information systems (Davenport 2000, Moon 2007). These systems need to be continuously reviewed and enhanced to meet new user requirements (Peng and Nunes 2009). Hence, these systems have evolved over time thanks to ERP developers, who have indentified and developed new functionalities for them. In some cases, these changes have been made to include new business processes in the ERP, while in other, they have been driven to connect ERP functionalities with legacy systems in the organisation or other in systems beyond the organisation. Thus, proposals about the integration of new functionalities and new interoperability requirements 
produce new developments in ERP systems.

The aim of this paper is to identify the role that interoperability plays in the evolution of ERP systems. To go about this, ERP systems have been firstly indentified within interoperability frameworks. Secondly, the initiatives in the ERP field driven by interoperability requirements have been identified from two perspectives: technological and business. Hence this paper is outlined as follows: Section 2 deals with interoperability; Section 3 describes ERP in the interoperability proposals; Section 4 describes the interoperability scope in ERP; Section 5 reviews the proposals in the ERP field driven by interoperability; finally, Section 6 summarises and concludes.

\section{Interoperability}

Enterprise Interoperability (EI) is a well-established area of applied research that addresses problems relating to the lack of interoperability of systems and applications in organisations, and proposes novel solutions for EI problems (Jardim-Gonzalves et al. 2013).

Different definitions can be found in the literature, and Table 1 summarises these definitions.

\section{“Insert Table 1 here”}

According to Vernadat (2010), it is important to not confuse interoperability with integration. When enterprise systems are integrated, they function in a coordinated and uniform manner; in other words, they become homogeneous systems. Interoperability does not require this, but that the otherwise autonomous systems are able to exchange and use each other's information and functions instead. According to Panetto and Molina (2008), integration is generally considered to go beyond mere interoperability to involve some degree of functional dependence. While interoperable 
systems can function independently, an integrated system loses significant functionality if the flow of services is interrupted. Chen (2008) indicates that interoperability implies co-existence, autonomy and federated environment, whereas integration refers more to the coordination, coherence and uniformisation concepts.

Studying previous definitions of interoperability in depth and identifying the components involved in interoperability are not easy tasks. For example, Gathner (2007) uses an Interoperability Reference Model with two levels (Real Word System and Information Systems) to analyse these interoperability components (Figure 1).

“Insert Figure 1 here”

Thus over the last few years, various interoperability frameworks have emerged with this proposal. These frameworks usually distinguish among different interoperability dimensions:

Levels of Information Systems Interoperability (LISI) (C4ISR 1998) was the first effort made towards an interoperability framework, which was developed by the U.S. C4ISR Architecture Working Group (AWG) in 1997. It is actually a maturity model to prescribe the requirement of a set of systems to be interoperable. It uses four different levels known as PAID (Procedures, Applications, Infrastructure and Data).

IDEAS interoperability framework (IDEAS 2005). The first European effort was the IDEAS interoperability framework, which also harnessed the idea that interoperability is achieved in multiple layers. The content of these layers formed the basis for the interoperability concerns defined in the INTEROP Enterprise Interoperability Framework.

ATHENA interoperability framework (AIF) (ATHENA 2004) The AIF was considered complementary to the IDEAS framework as it provides relevant research 
elements and solutions to interoperability issues, instead of stopping at defining these issues.

European Interoperability Framework (EIF) (IDABC 2008) proposes another categorisation of interoperability areas. In these areas, policies, standards and guidelines are presented to which enterprises should adhere to achieve interoperability.

Other proposals in the field of enterprise architecture or standards related to interoperability have also been made: a framework to develop interoperability of enterprise applications and software (Chen 2003); levels of functional compatibility (IEC TC65/290/DC); the Enterprise Architecture framework for enterprise integration used in interoperability proposals (GERAM -ISO 15704; Noran, 2011); the Computer Integrated Manufacturing-Systems Architecture-Framework for Enterprise Modelling (ENV 40003); a Model-Driven interoperability Architecture (MDA) (Panetto 2007); a reference architecture for Networked Enterprise Applications and Software (INTEROPNoE); architectures and methods to build interoperable enterprise systems (Vernadat 2007).

\section{ERP in the interoperability proposals}

ERP systems participate in interoperable systems. For this reason, it is important to locate them in the interoperability frameworks and interoperability levels to be able to clarify the role of ERP in the interoperable system. Moreover, this enables us to know about the interoperability frameworks' components that can influence ERP and can trigger changes (new proposals) in the ERP field.

The relationship between ERP systems and interoperability frameworks is summarised in the following table 2. The ERP Application indicates where the software ERP is located inside the levels or the framework, while the ERP Influences indicate the 
main components which inspire changes in the ERP field. It is important to clarify that we are locating the implemented software ERP and not other aspects of ERP projects, such as their design phases, customisation or change management, to name but a few.

"Insert Table 2 here”

This table shows the location of ERP within interoperability frameworks and at interoperability levels. It also shows the main components influencing ERP. Thus, from the ERP systems perspective, interoperability is a source of new proposals for new ERP functionalities. ERP as an application is influenced by other applications (e.g., legacy systems), by conceptual business models (e.g., virtual enterprises) and by technological proposals (e.g., SOA) (Figure 2).

Figure 2. Influences on ERP systems

\section{The interoperability scope in ERPs}

Davenport (2000) defines ERP systems as packages of computer applications that support many, even most, aspects of a company's information needs. These systems are general purpose systems designed for a wide range of enterprises (Xu 2011). They support the comprehensive management of financial, manufacturing, sales, distribution, human resources, and other aspects of business processes across the enterprise (Shtub 2001). Specifically, they are characterised primarily by their capability for service materials planning, order entry, distribution, general ledger, accounting and shop floor control (Wu 2011). Traditionally, ERP systems evolved from MRP II (Manufacturing Resource Planning) systems, which were designed to manage production facility’s orders, production plans and inventories (Markus et al. 2000). 
system (Davenport 2000; Lee et al. 2003; Moller 2005) are it:

- integrates all the company functions, processes and data by using a single database and by defining individual roles and views

- $\quad$ can be applied to most economic sectors

- $\quad$ is modular in design

- $\quad$ is based on the best practical process reference models.

ERP systems have evolved to become broader and more inclusive systems. In addition, their ongoing development has resulted in various types of ERP systems with a specific industry or sector focus. Examples are ERP systems that address vertical sectors such as aerospace, or services such as banking. These Industry-oriented ERPs (IERP) are system-designed for enterprises belonging to a given industry sector and they support specific business needs which are not covered by existing general purpose systems (Wu et al. 2009; Xu 2011). A similar concept is “vertical solutions”, defined by Moller (2005) as sets of standardised pre-configured systems with "add-ons” to match specific requirements.

Besides this classical perspective of ERP systems, we propose to use an interoperability perspective. The previous definition of interoperability (in Section 2) focuses on the interoperability subject as a kind of interaction among systems. In this sense, ERP, as systems, participates in these interactions. So it is necessary to identify three different situations (scope): 1) ERP is a modular product, and from this internal point of view, each module is a system. Thus, interoperability is produced internally among these modules; 2) ERP belongs to an enterprise system and co-exists with other 
legacy systems in this enterprise system of an organisation. From this enterprise system point of view, each software application used by the organisation is a system. Thus, interoperability is produced between ERP and other legacy systems; 3) different organisations use enterprise systems to interact among them, and ERP systems participate in these enterprise system networks. From this external point of view, each enterprise system is a system that interacts with others. Thus, interoperability is produced among enterprise systems and, consequently among ERPs, when these enterprise systems are supported by them (Table 3).

\section{“Insert table 3 here”}

Internal - Intra-application. As previously stated, one of the main characteristics of ERP systems is the integration of functions, processes and data throughout the enterprise. This is one of the reasons why ERP systems are being imposed as information systems for business management given their ability to not only automate and integrate the different business processes in the company, but to provide an integrated vision and new advantages in business management (Boza and Cuenca, 2011).

Different ERP modules have emerged to overcome the information exchange problems among various company areas, where heterogeneous systems hardly exchange internal company information. Therefore, the difficulties that legacy systems have to exchange information with each other within the company have, in many cases, been overcome by the implementation of ERP systems.

ERP translate these information exchange difficulties to an intra-application challenge where the different modules require intense information exchange.

Internal - Intra-organisational. Although ERP has replaced some of these legacy systems (e.g., accounting, billing, order entry, etc.), these companies have often 
found that they must still maintain other applications, which have to be integrated into the ERP system (Giachetti 2004). However, legacy systems are not always compatible with ERP systems. This interoperability must be addressed in the enterprise system. It is often difficult for an ERP system to be seamlessly integrated with another IS. The occurrence of this risk event may lead to poor data and business process integration, and to the creation of insulated technological islands (Peng and Nunes 2009).

Moreover, this internal (intra-organisational) interoperability involves not only a functional perspective, but also a geographical perspective were business units can be located at different sites. According to Markus et al. (2000), each different way in which the organisation can arrange the relationships among business units can be associated with a natural way of configuring ERP systems and managing multisite ERP implementation projects. Motivations for such enterprise systems may include the desire to coordinate and control the activities of geographically dispersed subsidiaries or to cut corporate information management costs. The integration of various information systems into a company-wide system, especially after mergers and acquisitions, is often quite an issue. From the subsidiary point of view, however, this is coercion which potentially affects local autonomy, and may even be at odds with local procedures (Benders et al. 2006).

External - inter-organisational. In order to improve integration and to expand its boundary beyond the enterprise, ERP II systems have been developed. Interoperability in extended supply chains is often enabled through enterprise portals, whose role is to facilitate the integration of various vendor and client systems into a company's ERP system (Michaelides and Papazian 2007). ERP II systems expand the ERP functionalities thanks to the involvement of other stakeholders outside the organisation (customers, suppliers or employees). ERP II systems provide tools for better decision 
making and to improve communication with external stakeholders. Some of the components included in these systems are: traditional ERP, e-business, enterprise application integration (EAI) characteristics, supply chain collaboration (SCM), customer relationship management (CRM) and knowledge management (Bond et al. 2000, Weston 2003, Lee et al. 2003, Moller 2005, Wu 2011).

Another step is the development of ERP III systems, which enables the transformation of an enterprise into a knowledge-based learning organisation (Xu 2011). According to Wood (2010), ERP III addresses the final domain of enterprise class applications by addressing the customer focus value proposition. It is an extension of technology capabilities which integrate collaboration with customers and the broader marketplace into the enterprise system as a borderless enterprise system.

Recently, Xu (2011) defined Entire Resource Planning (ERP), or Complete Resource Planning (CRP), as the integration of the ERP, ERPII and ERPIII concepts. Its design is extended to comprehensively encompass the resources used and produced by enterprises in different industrial sectors in the economic and societal development context.

\section{Proposals in the ERP field driven by interoperability}

The aim of this paper is to identify the role that interoperability plays in the evolution of ERP systems. A literature review of the proposals that impact ERP systems and interoperability issues classifies them according to two perspectives: proposals in the ERP field driven by interoperability from the technological perspective and proposals driven by a business perspective. 


\subsection{Technological proposals}

Web services and service-oriented architecture (SOA). Web services have emerged as the building blocks of SOA that support not only enterprise application integration (EAI) and business process management (BPM) within an organisation, but also B2B, collaboration based on the business process integration. By creating an integrative structure, EAI connects heterogeneous data sources, systems, and intra- or interenterprise applications. Service-oriented integration has evolved from EAI, where proprietary connections are replaced with standards-based connections on an Enterprise Service Bus (ESB) notion that is location-transparent and provides a flexible set of routing, mediation, monitoring and transformation capabilities (He and $\mathrm{Xu} 2011$ ). Those enterprise applications implemented or packaged as web services are loosely coupled and can be dynamically bound together while carrying out a business process. This is highly relevant to B2B collaborative processes in which business partnerships are often dynamically set up with interoperable web services that run on diverse platforms, and which communicate and collaborate over the Internet (Yeung 2011). These modular software pieces can be reused and reconfigured in new ways as business conditions change, therefore saving time and money for companies (Vijay 2011).

SOA and web services are emerging as a new trend in the development of new interoperable and agile business systems that will affect the current view of ERP systems (Vernadat 2007, Hofmann 2008, Atzori et al. 2010). The key for the development and implementation of SOA is services encapsulation and orchestration of applications through certain mechanisms to operate a complex business. However, cross infrastructures services access protection and relative services orchestration are still the bottleneck for SOA implementation. Li et al. (2010) address this subject and develop a 
business processes-oriented heterogeneous systems integration platform with the relative methodology for networked enterprises integration.

The ERP, SCM, and CRM software packages are critical elements of collaborative ebusiness systems and enterprise software systems products are becoming web servicesenabled. Therefore, many enterprise software vendors offer their products with web services interfaces to improve their interoperability (Chen et al. 2007).

Enterprise Services Architecture (ESA), the acronym for an enterprise ServiceOriented Architecture (SOA), has emerged as a new generation technology architecture in this area. Enterprise system applications using this Internet-based technology utilise ESA services from service providers as building blocks to be converted into a business system platform with reusable utility functionality. The hard system analysis and design functions, such as the system being extended to additional externally collaborating usergroups, become simpler (Woods and Mattern 2006).

Following on from this idea, new technological architectures to build ERPs based on web services have been proposed in recent years:

- EERP, End-to-End Resource Planning, where BPM and SOA have been combined as a core technology (Xu 2011). EERP is a business-centric approach to end-to-end integration and to the optimisation of business processes and services to: enhance business agility and adaptability to an ever-changing environment; improve business performance; sustain competitive advantages; ultimately create business value; accomplish the business objective (Li and Zhou 2008).

- GridERP. Grid computing is a new technology for distributed computing systems. A novel global enterprise system architecture based on OGSA (Grid Service Architecture), called GridERP, has been proposed for solving the 
problem of non-effective sharing of distributed resources and the interoperability issue on the global deployment of enterprise systems (Wang et al. 2008; Xu 2011).

- $\quad$ Federated ERP-systems. A federated ERP system (FERP system) is an ERP system that consists in system components which are distributed within a computer network. Overall functionality is provided by an ensemble of allied network nodes that collectively appear to the user as a single ERP system. Different ERP system components can be developed by different vendors. This approach contributes to improve company performance by providing companies the opportunity to combine software components of different vendors to meet their own software requirements more precisely (Brehm and Marx 2010;Asfoura et al. 2011). Asfoura et al. (2011) propose a FERP mall as a provider of a workflow reference model, which represents all the possible company scenarios (workflow descriptions). This FERP workflow combines web services from different providers of FERP to support the whole FERP business process in user companies. The next step could involve employing this architecture in interorganisational business process environments.

Cloud computing and software as a service (SaaS). Cloud computing often refers to Internet-based development and use of computing technology (Wang et al. 2012). According to Mell and Grance (2009), cloud computing includes three major delivery models: (1) Software as a Service (SaaS), (2) Platform as a Service (PaaS) and Infrastructure as a Service (IaaS).

Nowadays, cloud computing and SaaS are changing access to information in ERP systems and, subsequently, the way to access in an interoperability environment. Cloud 
computing service providers use virtualisation technology to virtually unify systems and to provide unified interfaces by different systems (e.g., ERP, CRM, etc.). If the supply chain is unified at the enterprise level, then the cloud computing service provider carries out the unification function, which is the equivalent to enterprise ERP system functionality. When the enterprise that participates in the supply chain works together to share information on the cloud platform, this leads to greater efficiencies as the members working in functional departments integrate across the complete process and gain better visibility. In supply chains, cloud computing optimally allocates information resources to reduce supply chain information distortion, accelerates information transmission speed and accuracy, and improves the overall competitiveness of the supply chain's role (Jun and Wei 2011). At this point, two situations emerge from the perspective of where ERP is located in relation to cloud (inside or outside the cloud). The first is to work with on-premises ERPs and to use SaaS solutions for complementary applications such as CRM or SCM, which must be integrated into the ERP (Sun et al. 2007). The second locates the ERP in the cloud; thus, a cloud ERP may have to be integrated into other on-premises legacy applications or other SaaS solutions. More than $70 \%$ of companies expect the SaaS solution to be integrated into their onPremises legacy applications (installed and run on computers on the premises -in the building- of the person or organisation using the software) or other SaaS solutions (AMR 2005; Narasimhan and Nichols 2011). Nonetheless, only 4\% have fully integrated their Cloud applications, and almost half have, at best, basic levels of integration, such as single sign-on (Narasimhan and Nichols 2011). Sun et al. (2007) deal with the integration of SaaS solutions with on-premise ERPs. This integration occurs in all three layers of the SaaS application: a) user interface integration, b) process integration and c) data integration. As a result of their research, they introduce a SaaS 
integration framework reference architecture based on a model-driven integration approach.

According to Hofmann (2008), in the near future we will see ERP systems run in the cloud, even for multi-billion dollar companies. The three underlying tenets are: a) standardising processes and design specifications, b) increasing computing utilisation, and c) reducing data centres through consolidation. However, this synergy between cloud computing and ERP is currently being explored (De Maria et al. 2011) and some drawbacks have been identified: ERP represents a significant source of competitive advantage, but if ERP becomes a commodity -the cloud model's central premise- it will limit a company’s ability to innovate (Hofmann and Woods 2010). In this sense, Elvesæter et al. (2010) proposes a software platform based on cloud-enabled innovation. They point out that the cloud is emerging as the new "business arena" where participants will join in by innovating and operating their networked enterprise business. Mobile information and communication technologies (ICT). On another front, mobile ICT are changing the way ERP will interact with the environment and explore new interoperability aspects, which will be integrated into ERP systems. Intelligent Wireless Web (IWW), Wireless Sensor Networks (WSNs) or Radio Frequency IDentification (RFID) technologies have promising industrial applications as they bridge the gap between traditional enterprise systems and the real world with more accurate information on the physical state and conditions (Koh et al. 2006, Haller et al. 2009, Soroor 2009). In line with this, the Internet of Things paradigm arises, which explores new interoperability aspects, where distributed intelligence for smart objects connects with ERPs (Atzori et al. 2010). Each particular application requires complex integration work to combine enterprise systems (ERPs) with those technologies, where sensor nodes update ERP data (Guinard et al. 2009). Martinez-Sala et al. (2009) present 
an example of this technology for a fresh product supply chain, where their functionality can be directly integrated into customer ERPs. Kong et al. (2009) introduce a methodology that uses event-driven service technology and active rule processing for the business process integration of ubiquitous enterprises. Such events are delivered continually and automatically from various internal or external business event sources, and include information systems, such as ERP and SCM systems, as well as real-time sensors, such as RFID tags.

\subsection{Business proposal}

One of the main elements in interoperability frameworks is the organisational aspect (Chen et al. 2008). An organisational infrastructure can also be calibrated to facilitate ‘jointness', a term used to describe cross-service cooperation. Functions must be able to communicate with each other in timely and effective ways. Interoperability should be a primary concern. Businesses have installed ERP systems to ensure company-wide communication. When employees understand how to use the ERP system, gain access to system information and have the authority to use information, 'jointness' should expand (Douglas and Strutton 2009).

The user requirements of a company will constantly change under highly dynamic and competitive market conditions. The implemented ERP system should, therefore, be continuously reviewed and enhanced in the post-implementation phase in order to meet new user requirements. However, it can be argued that this task may not always be carried out properly in many companies given the low flexibility of the ERP system, high reconfiguration costs, lack of in-house experts and insufficient support from system vendors and consultants. If this risk event occurs, the ERP system may gradually become less efficient to support user needs, which may have a significantly impact on business operational efficiency and ERP acceptance (Peng and Nunes 2009). 


\section{Business process management (BPM) and business process reengineering (BPR).}

Nowadays, new organisational models are being deployed, and tools like BPR strive to improve the overall blueprint of ERP systems through enhanced process integration, automation and optimisation (Samaranayake 2009). Among other trends in the ERP field, Moon (2007) highlights the emphasis placed on the intimate relation between BPR and a wide range of organisational changes accompanying ERP implementation. ERP systems normally focus on streamlining structured business processes, but new proposals emerge for semi-structured and unstructured processes in the networked businesses context (Koppenhagen and Maedche 2010). Operational processes of heterogeneous systems are controlled and integrated through meta-processes. Huang et al. (2008) propose a conflict-detecting mechanism (CDM) to assist process designers. This proposal uses EPC (Event-driven Process Chain) diagrams, which have become so popular in practical business applications because the leading ERP vendor, SAP AG, uses it to represent $\mathrm{R} / 3$ processes, and it has developed many analytical techniques for business process reengineering (BPR). Dörner et al. (2011) propose a business process modelling environment in the ERP systems context which enhances the descriptions of those services provided by SOA. These enhanced descriptions focus on organisationalspecific information. The process orchestration and the role of ERP are addressed in (Tewoldeberhan and Janssen 2008).

Manufacturing systems and e-maintenance. In these systems, Urdaneta et al. (2007) propose an architecture for the development of IAHLAs (Industrial Automation HighLevel Applications), which should fulfil the following extra-functional design criteria, among others: 1) interoperability: the architecture must be based on the standards supported by multiple vendors so that an organisation can choose between several products (e.g., middleware, databases and operating systems) with no effect on their 
applications; 2) use of existing systems: the architecture must provide mechanisms that allow the applications to access the existing enterprise information systems in the organisation (e.g., message-oriented middleware, transaction-processing monitors and ERP systems). Panetto (2008) and Blanc et al. (2008) describe challenges for manufacturing execution systems (MES), where the control system (the decisional subsystem) is considered the composition of a high-level management system (such as ERP) and a low-level control system.

The appearance of e-technologies optimises maintenance-related workflow and the need to integrate business performance, which imposes the following requirements in the maintenance area: openness, integration and collaboration with the other services of the e-enterprise (new ways of thinking for maintenance). e-Maintenance platforms are required to integrate e-maintenance services with other enterprise processes (integration with tools such as ERP and MES) (Iung et al. 2009).

Digital enterprises and virtual enterprises. The integration of ERP systems across the boundaries of organisations in the dynamic collaboration context is no trivial matter. The architecture required for dynamic network process management in instant virtual enterprises is outlined in Grefen et al. (2009). For digital enterprises, ERP systems play a decisive role for building a comprehensive digital enterprise information resources management system to ensure the smooth operation of enterprises and to make operational systems effective to help them achieve business functions and business goals (Sun et al. 2010). Virtual Enterprises are no longer mirrors of their counterparts in the physical world. Developments in this area bring about new means of working and a potentially new meaning to work (EC 2011), while ERP systems participate in the value chain (Gunasekaran and Ngai 2004). 
However, other organisational changes arise when adopting this technology to not lock companies into the rigid business processes of an ERP system. People in the enterprise and extended enterprise partners must be prepared to understand how to effectively utilise this technology, how it enables them to better perform their roles and responsibilities, and how this technology can fulfil company goals and objectives (An et al. 2008).

Reference models. Existing reference models provide valuable knowledge to move towards more dynamic reference information models, including the progress made by ERP vendors to make their reference models configurable. ERP vendors have access to the incorporated elements of a mass customisation strategy to help manage the enormous complexity of their detailed reference models by covering all the possible implementation variants (Verdouw et al. 2010). Blanc et al. (2007) tackle the heterogeneity problems in supply chains from a semantic and organisational perspective, who propose reference models and standards as a solution. Some frameworks for intercompany relationships (SCOR, CPFR, ISA95 and OAG) are used by ERP-system vendors to deliver further integration solutions (Hvolby and Trienekens 2010). Other proposals of reference models and meta models exist: those that intend to increase the efficiency of enterprise system implementations, which can be found in Dreiling et al. (2008); the model construction business processes in Shi et al. (2008); building a metadatabase in Babin and Cheung (2008).

Semantic integration. One of the problems with the automation of business processes is integration between different systems. It is precisely here where ontology plays a fundamental role in facilitating the interoperability of the systems involved. Semantic integration is an essential approach to deal with heterogeneity in large and dynamic enterprises. Solutions based on semantic web services and ontologies are promising and 
are being actively researched (Izza et al. 2008, Jagdev 2008, Grubic 2010, ParedesMoreno et al. 2010, Cardoso and Bussler 2011, Garcia-Crespo et al. 2011). The interaction among data sources in the ontology semantic model layer offers features like completeness, accurateness and efficiency (Liu et al. 2011).

Currently, existing solutions are based mainly on the use of some standards and also middleware to overcome the integration problem. These solutions generally fail for two reasons: they do not scale to large numbers of applications; they do not provide more flexibility and agility. Izza et al. (2008) propose a flexible approach called ODSOI (Ontology-Driven Service-Oriented Integration), which combines both service-oriented architectures and ontologies and aims to correctly deal with some application integration issues.

Product lifecycle management (PLM). The need to integrate business and technical information systems, by allowing partners to collaborate effectively in creating innovative products, has motivated the design and deployment of a novel integration framework for PLM (Vijay 2011). PLM is being explored in collaborative value chains (Chiang 2007), where systems (CAD, CAPP, ERP, etc.) can be physically separated and have different owners. Marchetta et al. (2011) propose a PLM system which adopts a proactive role for integrating information and achieving interoperability. Newman and Nassehi (2007) investigate interoperability between CAD/CAM/CNC and ERP systems. Babič et al. (2010) examine interoperability between CAD and ERP systems to build an information model. Finally, Gulledge et al. (2010) propose a composite application design to link condition-based maintenance (CBM) and PLM.

Supply chain management (SCM). SCM can be integrated with ERP systems to cover, among others, operational planning, statistics and personnel management (Coronado et al. 2009). Koh et al. (2006) investigate this integration of SCM and ERP 
systems to achieve a successful supply chain in the twenty-first century. According to this research, most ERP system providers have enhanced their products to include salesforce automation, data warehousing, document management, after-sales service and support. Integration of ERP and SCM is a natural and necessary process in strategic and managerial considerations. The integration of SCM, supplier relationship management (SRM) and ERP provide the company a chance to build effective processes with the suppliers they trust with a view to gaining the maximum return on relationship with all their suppliers. Breaking the traditional decentralised system and introducing the concept of a single, integrated plan, which a company could work on together with their suppliers, leads to cost reductions and increased efficiency. This unique practice suits new market requirements. However, before any company can be effectively linked into an agile supply chain, their own internal process must be re-engineered so that its ERP system plays a key role.

Cândido et al. (2009) deals with the research challenges associated with the application of SOA in reconfigurable supply chains, where global company agility is always limited by its least agile building block; that is, all levels of the computer integrated manufacturing (CIM) pyramid, from ERP to shop-floor level, need to be agile and have to interact in a seamless, synchronised manner.

Information Technology (IT) has been considered one of the pillars supporting information management in the supply chain. However, while IT addresses some SCM issues, it is also a source of vulnerability in the supply chain. Therefore, consideration should be made as to how to implement IT into the supply chain in order to improve robustness and resilience by considering that IT can become another source of instability (Verissimo 2009). 
Some proposals have dealt with the integration of ERP into different SCM sectors, such as the fashion industry (Lo 2008), the perishable products industry (Verdouw et al. 2010) or the construction industry (Cheng 2010).

Decision Support (DS) and Business Intelligence (BI). One challenge in interoperable enterprise systems is operations optimisation via co-decision and co-ordination (Vernadat 2007). In this sense, an analytical layer has been included to enhance and extend central ERP functions by providing decision support to manage relations and corporate issues. The process metrics, which help managers make decisions, must be defined measured and analysed, and targets must be set. ERP systems can either include these metrics (Forslund 2010) or provide this information to analytical tools in data warehouses as the basic environment for decision support systems (DSS) (Liu and Liu 2010).

Traditionally, it is important to highlight the expansion of evolving ERP systems to support business processes from operational to strategic levels. This expansion enables the implementation of more complex decision and logical derivation processes, and requires the use of new technologies and methods to support the more intelligent behaviour of ERP systems (Smaizys and Vasilecas 2009). Botta-Genoulaz et al. (2005) review ERP integration with other information technologies, where the general goal of that integration was to make decision-making processes easier (integration between ERP and: advanced planning scheduling-APS systems; manufacturing execution systems; warehouse management systems-WMS; logistics management systems-LMS). In addition, Boza et al. (2009) highlight the importance of decision support and the trans-organisational objectives in ERP planning.

Collins and Sadeh (2009) deal with new kinds of decision support systems, namely the trading agent. This involves systems that can continuously integrate large 
volumes of information into detailed economic models, and make or recommend decisions that maximise customer utility and increase a company's profit in a competitive environment.

Smaizys and Vasilecas (2009) propose a Business Rules-Based Agile ERP Systems Development. This work focuses on their research into ERP development; here it is possible to ensure different levels of agility by instantly deploying changes in the business policy, resulting in an immediate reaction to changes on the market or in competition by changing existing business rules and by introducing new rules (in the ERP) by business analysts, and not by programmers. The advances made in this line of work can extend the business rule management system (BRMS) layer beyond a single ERP to inter-enterprise business rules so that the changes made to these rules can be agilely adopted by ERP participants. According to Duan and Xu (2012), currently most research into Business Intelligent (BI) in industrial informatics is done for quality control purposes. Given the automatic enterprise systems process trend, most related applications will be integrated with enterprise systems for decision making and for reducing future manual interventions.

Table 4 summarizes the above classification of these subjects.

(INSERT TABLE 4 HERE)

The previous proposals identify the drive that some interoperability aspects apply to the ERP field. Technologies development allows their use to improve interoperability at the ERP technical level, and new business proposals introduce functional changes into ERPs.

(INSERT FIGURE 3 HERE) 
Thus, technologies and new business models are changing the ERP field from classical ERP as information system integrators to a new generation of fully interoperable ERP (Figure 3).

\section{Conclusions}

New proposals are arising in the interoperability field, which influence the ERP field. The analysis of interoperability frameworks and interoperability levels has provided the knowledge of components that can inspire changes in ERP applications. These changes stem mainly from technological and business interoperability proposals.

The literature review has helped to identify proposals that impact on ERP systems and interoperability according to the technological and business perspectives.

New technologies are being used in ERP systems to facilitate interoperability because they allow the building of new business models. SOA and web services are the main drivers in this challenge, where new technological architectures to build ERP have been proposed, such as, EERP, GridERP and Federated ERP systems. Furthermore, cloud computing technologies, mobile ICT, and especially the Internet of Thing paradigm, provide new directions for ubiquitous enterprises.

Thus, new business models are being deployed in interoperable enterprise systems where ERP systems play a key role. Using BPR, reference models and frameworks for intercompany relationships are just some of the initiatives that are changing business models toward digital enterprises, virtual organisations or collaborative value chains. Also, new decision models arise for interoperable environments. The analytical layer for inter-organisational processes must be fed by enterprise systems. In this sense, interoperability is required between ERPs and tools to support the inter-organisational decision process in order to accomplish better decision 
making (such as, decision support systems, data warehouses, business rule management systems and business intelligence).

The main benefit of interoperability in the ERP field is that interoperability is a source of new proposals for new ERP functionalities, which in turn produces feedback on the interoperability field. However, some drawbacks arise. Changes in ERP systems have been slow due to, among others, their excessive complexity and inherently low levels of flexibility. Hence proposals driven by interoperability are slowly being incorporated. New technical proposal can produce high cost in its fulfilment. New business interoperability proposals also can generate a dilemma: do we include the new functionality proposed in the ERP system, or do we inter-operate with an external solution?

The findings reported in this paper confirm that ERP systems evolve towards more interoperable environments. ERP developers have important challenges in their agendas propelled by interoperability: a) Monitor and evaluate interoperability proposals to plan new develops on the ERP systems. b) Include the interoperability issue from the early steps of any new development or c) Train developers and consultants in the interoperability matter.

This paper is useful for scientific community in the ERP field because ERP researchers have an important extension of their field to address interoperability proposals. In addition, it is also useful for the interoperability researchers because ERP systems are significantly involved in many interoperability projects.

Interoperability is changing the way businesses are being run, and ERP systems are changing to adapt to the current stream of interoperability. ERP systems are on the crest of the wave of change, which is driving businesses towards inter-operational models. 


\section{Acknowledgment}

This research has been carried out in the framework of the "Programa de Apoyo a la Investigación y Desarrollo (PAID-00-12)” from the Universitat Politècnica de València (Spain).

\section{References}

AMR, 2005. Research Report: Software as a Service: Managing Buyer Expectations as We Pass the Tipping Point from Novelty to Necessity.

An, L., Yan, J. and Tong, L., 2008. Methodology for Web Services Adoption Based on Technology Adoption Theory and Business Process Analyses. Tsinghua Science \& Technology, 13(3), 383-389.

Asfoura, E., Neumann, R., Kassem, G. and Dumke, R., 2011. The identifying and adapting of FERP mall form and roles for more trust by marketing of distributed FERP components. Procedia Computer Science, 3, 11-22.

ATHENA, 2004 [online]. Available from: http://interoplab.eu/ei_public_deliverables/athenadeliverables/list-of-public-deliverablessubmitted-during-the-athena-project/?searchterm $1 / 4$ ATHENA

Atzori, L., Iera, A. and Morabito, G., 2010. The Internet of Things: A survey. Computer Networks, 54, 2787-2805.

Babič, N.Č., Podbreznik, P. and Rebolj, D., 2010. Integrating resource production and construction using BIM. Automation in Construction, 19(5), 539-543.

Babin, G. and Cheung, W., 2008. A Metadatabase-supported shell for distributed processing and systems integration. Knowledge-Based Systems, 21(7), 672-680.

Benders, J., Batenburg, R. and Blonk, H., 2006. Sticking to standards; technical and other isomorphic pressures in deploying ERP-systems. Information \& Management, 43 , 194-203.

Blanc, P., Demongodin, I. and Castagna, P., 2008. A holonic approach for manufacturing execution system design: An industrial application. Engineering Applications of Artificial Intelligence, 21(3), 315-330. 
Blanc, S., Ducq,Y. and Vallespir, B., 2007. Evolution management towards interoperable supply chains using performance measurement. Computers in Industry, 58 (7), 720-732

Bond, B.A., Genovese, Y. and Zrimsek, B., 2000. The Transition to ERP II: Meeting the Challenges. GartnerGroup.

Botta-Genoulaz, V., Millet, P.A. and Grabot, B., 2005. A survey on the recent research literature on ERP systems. Computers in Industry, 56 (6), 510-22.

Boza A. and Cuenca L., 2011. Open and Closed Practicals for Enterprise Resource Planning (ERP) Learning. Software Industry-Oriented Education Practices and Curriculum Development: Experiences and Lessons, 138-152.

Boza A., Ortiz A., Vicens E. and Poler R., 2009. A Framework for a Decision Support System in a Hierarchical Extended Enterprise Decision ContextEnterprise Interoperability. Lecture Notes in Business Information Processing, 38(2), 113124

Brehm, N. and Marx J., 2010. Federated ERP-systems on the basis of Web Services and P2P networks. Int. J. Information Technology and Management, 9 (1),75-89.

C4ISR, 1998. Architectures working group: levels of information systems interoperability(LISI) ) [online]. Available from: http://www.eng.auburn.edu/*hamilton/security/DODAF/LISI.pdf

Cândido, G., Barata, J., Colombo, A.W. and Jammes, F., 2009. SOA in reconfigurable supply chains: A research roadmap. Engineering Applications of Artificial Intelligence, 22(6), 939-949.

Cardoso, J. and Bussler, C., 2011. Mapping between heterogeneous XML and OWL transaction representations in B2B integration. Data \& Knowledge Engineering, 70(12), 1046-1069

Chen, D., Doumeingts,G., 2003. European initiatives to develop interoperability of enterprise applications-basic concepts, framework and roadmap. Annual Reviews in Control, 27, 153-162

Chen, D., Doumeingts, G. and Vernadat, F., 2008. Architectures for enterprise integration and interoperability: Past, present and future. Computers in Industry, 59, 647-659.

Chen, M., Zhang, D. and Zhou, L., 2007. Empowering collaborative commerce with Web services enabled business process management systems. Decision Support Systems, 43(2), 530-546. 
Cheng, J. C. P., Law, K. H., Bjornsson, H., Jones, A. and Sriram, R.,2010. A service oriented framework for construction supply chain integration. Automation in Construction, 19(2), 245-260

Chiang, T-A. and Trappey, A., 2007. Development of value chain collaborative model for product lifecycle management and its LCD industry adoption. International Journal of Production Economics, 109, 90-104

Collins, J. and Sadeh,N., 2009. Introduction to special section: Supply chain trading agent research. Electronic Commerce Research and Applications, 8(2), 61-62

Coronado , A., Lalwani, C., Coronado „E. and Coronado ,C., 2009. Facilitating multimodal logistics and enabling information systems connectivity through wireless vehicular networks. International Journal of Production Economics, 122(1), 229-240

Davenport, T.H., 2000. Mission critical: realizing the promise of enterprise systems. Harvard Business School Press, Boston, Massachusetts.

De Maria, F., Briano, C., Brandolini, M., Briano, E. and Revetria, R., 2011. Marketleader ERPs and cloud computing: a proposed architecture for an efficient and effective synergy. Proceedings of the 10th WSEAS international conference on Applied computer and applied computational science

Dörner, C., Yetim, F., Pipek, V. and Wulf, V., 2011. Supporting business process experts in tailoring business processes. Interacting with Computers, 23(3), 226238.

Douglas, M.A. and Strutton, D., 2009. Going “purple”: Can military jointness principles provide a key to more successful integration at the marketing-manufacturing interface? Business horizons, 52(3), 251-263.

Dreiling, A., Rosemann, M., Van Der Aalst, W.M.P. and Sadiq, W., 2008. From conceptual process models to running systems: A holistic approach for the configuration of enterprise system processes. Decision Support Systems, 45(2), 189-207.

Duan L. and Xu L.D. 2012. Business Intelligence for Enterprise Systems: A Survey. IEEE Transactions on Industrial Informatics, 8(3), 679-687

EIF. 2004. European interoperability framework, white paper. Brussels: February 2004. http://www.comptia.org. 
Elvesæter, B., Berre, A-J., Man, H. and Li, M-S., 2010. Networked Enterprise Transformation and Resource Management in Future Internet Enabled Innovation Clouds, Enterprise Interoperability IV, Springer

Forslund H., 2010. ERP systems’ capabilities for supply chain performance management. Industrial Management \& Data Systems, 110 (3), 351-367.

Garcia-Crespo, A., Ruiz-Mezcua, B., Lopez-Cuadrado, J.L. and Gonzalez-Carrasco, I., 2011. Semantic model for knowledge representation in e-business. KnowledgeBased Systems, 24(2), 282-296.

Gathner, 2007. Preparation for Update European Interoperability Framework 2.0 FINAL REPORT

Giachetti, R.E., 2004. A framework to review the information integration of the enterprise. International Journal of Production Research, 42 (6), 1147-1166

Grefen, P., Mehandjiev, N., Kouvas, G., Weichhart, G. and Eshuis, R., 2009. Dynamic business network process management in instant virtual enterprises. Computers in Industry, 60(2), 86-103.

Grubic,T.,Fan,I-S.,2010. Supply chain ontology: Review, analysis and synthesis. Computers in Industry, 61(8), 776-786

Gunasekaran, A. and Ngai, E.W.T., 2004. Virtual Supply-Chain management. Production Planning and Control, 15 (6), 584-595.

Guinard,D., Trifa,V., Pham,T. and Liechti,O., 2009. Towards Physical Mashups in the Web of Things. 6th International Conference on Networked Sensing Systems.

Gulledge, T., Hiroshige, S. and Iyer, R., 2010. Condition-based Maintenance and the product improvement process. Computers in Industry, 61(9), 813-832.

Haller,S., Karnouskos, S. and Schroth, C., 2009. The Internet of Things in an Enterprise Context. Future Internet - FIS 2008, 14-28.

He, W., Xu, L.D., 2011. Integration of Distributed Enterprise Applications: A Survey. IEEE Transactions on Industrial Informatics, 99, 1-9

Hofmann, P., 2008. ERP is Dead, Long Live ERP. IEEE Internet Computing, 2 (4), 8488.

Hofmann, P. and Woods, D., 2010. Cloud Computing: The Limits of Public Clouds for Business Applications. IEEE Internet Computing, 14(6), 90-93.

Huang, S., Chu, Y., Li, S. and Yen, D.C., 2008. Enhancing conflict detecting mechanism for Web Services composition: A business process flow model 
transformation approach. Information and Software Technology, 50(11), 10691087.

Hvolby, H-H. and Trienekens, J. H., 2010. Challenges in business systems integration. Computers in Industry,61(9), 808-812

IDABC, 2008. European interoperability framework draft version 2.0 [online] http://ec.europa.eu/idabc/servlets/Docb0db.pdf?id1/431597

IDEAS, 2005. IDEAS roadmaps [online]. Available from: http://interopvlab.eu/ei_public_deliverables/ideas-deliverables/list-of-ideasdeliverables/?searchterm¹/4IDEAS

IEEE, 1990. Standard Computer Dictionary- A Compilation of IEEE Standard Computer Glossaries

Iung, B., Levrat, E., Marquez, A.C. and Erbe, H., 2009. Conceptual framework for eMaintenance: Illustration by e-Maintenance technologies and platforms. Annual Reviews in Control, 33(2), 220-229.

Izza, S., Vincent, L. and Burlat, P., 2008. Exploiting semantic web services in achieving flexible application integration in the microelectronics field. Computers in Industry, 59(7), 722-740.

Jagdev, H.,Vasiliu,L.,Browne,J. and Zaremba,M., 2008. A semantic web service environment for B2B and B2C auction applications within extended and virtual enterprises. Computers in Industry, 59(8), 786-797

Jun,C., Wei,M. Y., 2011. The Research of Supply Chain Information Collaboration Based on Cloud Computing, Procedia Environmental Sciences, 875-880

Koh, S.C.L., Saad, S. and Arunachalam, S., 2006. Competing in the 21st century supply chain through supply chain management and enterprise integration. International Journal of Physical Distribution \& Logistics Management, 36 (6), 455-65.

Kong, J., Jung, J. and Park, J., 2009. Event-driven service coordination for business process integration in ubiquitous enterprises. Computers \& Industrial Engineering, 57(1), 14-26.

Konstantas, D., Bourrières, J-P., Leonard, M. and Boudjlida, N., 2005. Interoperability of Enterprise Software and Applications

Koppenhagen, N. and Maedche, A., 2010. Anatomy of Business Networks: Future Internet Enterprise Systems Accelerating Procurement Interoperability. Submitted to the ENSEMBLE Call for Contributions on "Research on Future 
Internet Enterprise Systems and Scientific Foundations of Enterprise Interoperability”.

Lee, J., Siau, K. and Hong, S., 2003. Enterprise Integration with ERP and EAI. Communications of the ACM, 46 (2), 54-60.

Li, B. and Zhou, W., 2008. Research and Design of EERP: End-to-End Resource Planning Based on SOA and BPM. WiCOM '08. 4th International Conference on Wireless Communications, Networking and Mobile Computing, 1-3

Li,Q., Zhou,J., Peng, Q-R., Li,C-Q., Wang,C., Wu, J. and Shao, B-E., 2010. Business processes oriented heterogeneous systems integration platform for networked enterprises. Computers in Industry, 61(2), 127-144

Liu B., Cao, S.G., He, W., 2011. Distributed data mining for e-business. Information Technology and Management, 12, 67-79

Liu, Q. and Liu, G., 2010. Research on the Framework of Decision Support System Based on ERP Systems. Second International Workshop on Education Technology and Computer Science, 704-707.

Lo, W-S.,Hong, T. and Jeng, R., 2008. A framework of E-SCM multi-agent systems in the fashion industry. International Journal of Production Economics, 114(2), 594-614

Marchetta, M.G., Mayer, F. and Forradellas, R.Q., 2011. A reference framework following a proactive approach for Product Lifecycle Management. Computers in Industry, 62(7), 672-683.

Martínez-Sala, A. S.,Egea-López, E.,García-Sánchez, F. and García-Haro,J., 2009. Tracking of Returnable Packaging and Transport Units with active RFID in the grocery supply chain. Computers in Industry, 60 (3),161-171.

Markus, M.L., Tanis, C., and van Fenema, P.C., 2000. Multisite ERP Implementations. Communications of the ACM, 43 (4), 42-46.

Mell P, Grance T., 2009. The NIST definition of cloud computing. National Institute of Standards and Technology. Retrieved from http://csrc.nist.gov/groups/SNS/cloud-computing/

Michaelides, Z.M. and Papazian, A., 2007. Benefits of clustering for SME’s suppliers in the aerospace and defence sector through the adaptation of enterprise portals. International Journal of Services and Operations Management, 3 (2), 152-171.

Moller, C., 2005. ERP II: a conceptual framework for next-generation enterprise systems. Journal of Enterprise Information Management, 18 (4),483-497. 
Moon, Y.B., 2007. Enterprise Resource Planning (ERP): a review of the literature. International Journal of Management \& Enterprise Development, 4(3),235-264. Narasimhan, B. and Nichols, R., 2011. State of Cloud Applications and Platforms: The Cloud Adopters’ View. Computer, 44 (3), 24-28.

Newman, S.T. and Nassehi, A., 2007. Universal Manufacturing Platform for CNC Machining. CIRP Annals - Manufacturing Technology, 56(1), 459-462.

Noran O., Bernus P., 2011. Effective Disaster Management: An Interoperability Perspective. On the Move to Meaningful Internet Systems: OTM 2011 Workshops Lecture Notes in Computer Science 7046, 112-121.

Panetto H., 2007. Towards a Classification Framework for Interoperability of Enterprise Applications. International Journal of Computer Integrated Manufacturing, 20 (8), 727-740

Panetto H. and Molina, A., 2008. Enterprise integration and interoperability in manufacturing systems: Trends and issues. Computers in Industry, 59 (7), 641646.

Paredes-Moreno,A., Martínez-López,F. J. and Schwartz, D. G., 2010.A methodology for the semi-automatic creation of data-driven detailed business ontologies. Information Systems, 35 (7), 758-773.

Peng, G.C. and Nunes M.B., 2009. Surfacing ERP exploitation risks through a risk ontology. Industrial Management \& Data Systems, 109 (7), 926-942.

Jardim-Goncalves, R., Grilo,A. Agostinho, C., Lampathaki, F. and Charalabidis, Y., 2013, Systematisation of Interoperability Body of Knowledge: the foundation for Enterprise Interoperability as a science. Enterprise Information Systems, 7 (1), 7-32

Samaranayake, P., 2009. Business process integration, automation, and optimization in ERP. Business Process Management Journal, 15 (4), 504-526.

Shi, J.J., Lee, D. and Kuruku, E., 2008. Task-based modeling method for construction business process modeling and automation. Automation in Construction, 17(5), 633-640.

Shtub,A., 2001. A framework for teaching and training in the Enterprise Resource Planning (ERP) era. International Journal of Production Research, 39 (3),567576

Smaizys, A. and Vasilecas, O., 2009. Business Rules Based Agile ERP Systems Development. Informatica, 20 (3), 439-460. 
Soroor, J., Tarokh, M. and Shemshadi, A., 2009. Initiating a state of the art system for real-time supply chain coordination. European Journal of Operational Research, 196 (2), 635-650

Sun, W., Zhang, K., Chen, S-K., Zhang, X. and Liang, H., 2007. Software as a Service: An Integration Perspective. Service-Oriented Computing - ICSOC 2007 Lecture Notes in Computer Science, 4749, 558-569

Sun, J. and Cheng, H., 2010. Research on Model of Digital Enterprises Information Resources Management System. International Conference on Management and Service Science.

Tewoldeberhan, T. and Janssen, M., 2008. Simulation-based experimentation for designing reliable and efficient Web service orchestrations in supply chains. Electronic Commerce Research and Applications, 7 (1), 82-92

Urdaneta, G., Colmenares, J.A., Queipo, N.V., Arapé, N., Arévalo C., Ruz, M., Corzo, H. and Romero, A., 2007. A reference software architecture for the development of industrial automation high-level applications in the petroleum industry. Computers in Industry, 58, 35-45

Verdouw, C. N., Beulens, A. J. M., Trienekens, J. H. and Wolfert, J., 2010. Process modelling in demand-driven supply chains: A reference model for the fruit industry. Computers and Electronics in Agriculture, 73 (2), 174-187

Vernadat F.B., 2007. Interoperable enterprise systems: Principles, concepts, and methods. Annuals Reviews in Control, 31,137-145.

Vernadat F.B., 2010. Technical, semantic and organizational issues of enterprise interoperability and networking. Annual Reviews in Control, 34, 139-144

Verissimo, J., 2009. The new supply chain's frontier: Information management. International Journal of Information Management,29 (5), 372-379

Vijay, S., 2011. An integration framework for product lifecycle management. Computer-Aided Design, 43(5), 464-478.

Wang H., He W., Wang F.K., 2012. Enterprise cloud service architectures. Information Technology and Management, 13, 445-454

Wang T-L., Su, C-H., Tsai, P-Y., Liang, T-Y. and Wen-Hsiung, 2008. Development of a GridERP Architecture: Integration of Grid Computing and Enterprise Resources Planning Application. WiCOM '08. 4th International Conference on Wireless Communications, Networking and Mobile Computing, 1-4 
Weston, F.C., 2003. ERP II: The extended enterprise system. Business Horizon, November-December, 49-55

Wood, B. 2010. ERP vs. ERP II vs. ERP III Future Enterprise Applications. http://www.r3now.com/erp-vs-erp-ii-vs-erp-iii-future-enterprise-applications

Woods, D. and Mattern, T., 2006. Enterprise SOA: Designing IT for business information. O’Reilly Media Inc.

Wu S.L, Xu L. and He W., 2009. Industry-oriented enterprise resource planning. Enterprise Information System,. 3 (4), 409-424

Wu, W., 2011. Segmenting and mining the ERP users’ perceived benefits using the rough set approach. Expert Systems with Applications, 38, 6940-6948

Xu, L.D., 2011. Enterprise Systems: State-of-the-Art and Future Trends. IEEE Transactions on Industrial Informatics, 7 (4), 630-640

Yeung, W.L., 2011. A formal and visual modeling approach to choreography based web services composition and conformance verification. Expert Systems with Applications, 38(10), 12772-12785. 
Table 1. Definitions of interoperability

Source

Definitions of Interoperability

IEEE, 1990

C4ISR, 1998

Chen and

Doumeingths, 2003

Konstantas et al., 2005

Vernadat, 2007

IDABC, 2008

Chen et al., 2008 exchanged. from the customer or user. adhering to common standards.
Interoperability is the ability of two or more systems or components to exchange information and to use the information that has been

It is the ability of systems, units or forces to provide services to and accept services from other systems, units or forces, and to use the services so exchanged to enable them to operate effectively together.

Interoperability can be considered, roughly speaking, as the ability of a system to use functionalities of another (possibly remote) system.

Interoperability in enterprise applications as the ability of a system or a product to work with other systems or products without special effort

Interoperability refers to the ability of a system (or process) to use information and/or functionality of another system (or process) by

It implies the ability of information and communication technology (ICT) systems and of the business processes they support to exchange data and to enable sharing of information and knowledge.

It is "the ability to (1) communicate and exchange information; (2) use the information exchanged; (3) access the functionality of a third system". This definition is not limited to different organisations, but may also refer to different enterprise systems within the same organisation.

Table 2. Relationship between ERP systems and interoperability frameworks 


\begin{tabular}{|c|c|c|c|c|c|}
\hline Reference & Levels or Framework used: & $\begin{array}{l}\text { Levels or Framework } \\
\text { components: }\end{array}$ & $\begin{array}{c}E R P \\
\text { Application }\end{array}$ & $\begin{array}{c}\text { ERP } \\
\text { Influences }\end{array}$ & Description \\
\hline LISI & $\begin{array}{l}\text { LISI Reference Model } \\
\end{array}$ & $\begin{array}{l}\text { Enterprise } \\
\text { Domain } \\
\text { Functional } \\
\text { Connected } \\
\text { Isolated }\end{array}$ & $\mathrm{x}$ & $\mathrm{x}$ & $\begin{array}{l}\text { ERPs are in the Domain level, although their objective is always to reach the enterprise } \\
\text { level. It also is influenced by the functional level, with which it interacts with other } \\
\text { programmes in a distributed manner. }\end{array}$ \\
\hline IDEAS & $\begin{array}{l}\text { Enterprise interoperability } \\
\text { framework }\end{array}$ & $\begin{array}{l}\text { Barriers: } \\
\text { Conceptual } \\
\text { Technological } \\
\text { Organisational } \\
\text { Levels } \\
\text { Business } \\
\text { Process } \\
\text { Service } \\
\text { Data }\end{array}$ & $\mathrm{x}$ & $\begin{array}{l}\mathrm{X} \\
\mathrm{x} \\
\mathrm{x} \\
\mathrm{x}\end{array}$ & $\begin{array}{l}\text { ERP is located at the process level and is influencied by the business level and the service } \\
\text { level. ERP must also overcome technological interoperability barriers and must be adapted } \\
\text { to overcome conceptual and organisational barriers. }\end{array}$ \\
\hline ATHENA & Interoperability framework & $\begin{array}{l}\text { Conceptual Level } \\
\text { Application Level } \\
\text { Technical Level }\end{array}$ & $\mathrm{x}$ & $\mathrm{x}$ & $\begin{array}{l}\text { ERP are located at the application level. They are influenced firstly by the conceptual level } \\
\text { where business models are reflected, and secondlyby the technical level and their new } \\
\text { proposal. }\end{array}$ \\
\hline EIF & Interoperability levels & $\begin{array}{l}\text { Technical } \\
\text { Semantic } \\
\text { Organisational }\end{array}$ & $\mathrm{X}$ & $\begin{array}{l}\mathrm{x} \\
\mathrm{x}\end{array}$ & $\begin{array}{l}\text { ERP are at the technical level. They are influenced by the semantic level and the } \\
\text { organisational level. }\end{array}$ \\
\hline Chen, 2003 & Interoperability levels & $\begin{array}{l}\text { Business } \\
\text { Knowledge } \\
\text { ICT System }\end{array}$ & $\mathrm{X}$ & $\begin{array}{l}x \\
x \\
x\end{array}$ & $\begin{array}{l}\text { The interoperability of the highest levels is technically supported by the ICT System, which } \\
\text { it is built following the models of interoperability levels (Business and Knowledge). ERP } \\
\text { systems are located in the ICT system and are influenced by other components in the ICT } \\
\text { system and by the higher level components (Business and Knowledge). }\end{array}$ \\
\hline
\end{tabular}




\begin{tabular}{|c|c|c|c|c|c|}
\hline $\begin{array}{l}\text { IEC } \\
\text { TC65/290/DC }\end{array}$ & Compatibility levels & \multicolumn{3}{|l|}{$\begin{array}{l}\text { Incompatibility } \\
\text { Coexistence } \\
\text { Interconnectability } \\
\text { Interworkability }\end{array}$} & $\begin{array}{l}\text { ERP systems are located at the interoperability level because they are systems with } \\
\text { functional aplication compatibilty. These systems can move towards a interchangeability } \\
\text { level when a module can be interchanged by other third party. }\end{array}$ \\
\hline $\begin{array}{l}\text { GERAM } \\
\text { (ISO 15704) }\end{array}$ & GERAM framework: & $\begin{array}{l}\text { (Other compontents in high } \\
\text { Enterprise Engineering } \\
\text { Tools } \\
\text { Enterprise Models } \\
\text { Enterprise Modules } \\
\text { Enterprise Operational } \\
\text { Systems }\end{array}$ & $X$ & $\begin{array}{l}X \\
X\end{array}$ & $\begin{array}{l}\text { This is a framework for enterprise integration. However, it has been used for the } \\
\text { interoperability proposal. ERP is located in the Enterprise Operation System, which } \\
\text { supports the company's operation, and must be built to support Enterprise Models and } \\
\text { Enterprise modules. }\end{array}$ \\
\hline ENV 40003 & Framework (Axis) & $\begin{array}{l}\text { Enterprise model phase } \\
\text { Enterprise model view } \\
\text { Genericity (generic, partial, } \\
\text { particular) }\end{array}$ & & $\begin{array}{l}X \\
X \\
X\end{array}$ & $\begin{array}{l}\text { It is also a modelling framework for enterprise integration. All the axes influence ERP, but } \\
\text { genericity is very important in the ERP design since ERP is developed as a generic or a } \\
\text { partial view that must subsequently adapt to a particular design in each implementation in a } \\
\text { organisation. }\end{array}$ \\
\hline $\begin{array}{l}\text { Model driven } \\
\text { interoperability } \\
\text { architecture } \\
\text { (MDA) }\end{array}$ & Architecture Levels & $\begin{array}{l}\text { CIM -Computation } \\
\text { Independent Model } \\
\text { PIM - Platform } \\
\text { Independent Model } \\
\text { PSM - Platform Specific } \\
\text { Model }\end{array}$ & $X$ & $\mathrm{X}$ & $\begin{array}{l}\text { ERP is located at the PSM level when it is implemented in an organisation. However, ERP } \\
\text { is designed to be used in different platforms, and is consequently built from the PIM level. }\end{array}$ \\
\hline $\begin{array}{l}\text { INTEROP- } \\
\text { NoE }\end{array}$ & Reference Arquitecture & $\begin{array}{l}\text { Enterprise Model } \\
\text { System Model } \\
\text { Architecture (Ontologies) }\end{array}$ & $X$ & $\mathrm{X}$ & $\begin{array}{l}\text { Interoperability lies between systems (it includes the system model and architecture) } \\
\text { where ERP participates. The system model is influenced by the business model and is } \\
\text { conditioned by the architecture. }\end{array}$ \\
\hline $\begin{array}{l}\text { Vernadat } \\
2007\end{array}$ & Integration levels & $\begin{array}{l}\text { Business } \\
\text { Application } \\
\text { Physical system integration }\end{array}$ & $X$ & $\mathrm{X}$ & $\begin{array}{l}\text { They are the integration levels used to build interoperable enterprise systems. ERPs are at } \\
\text { the application level supported by physical system integration and support the business } \\
\text { level. }\end{array}$ \\
\hline
\end{tabular}


Table 3: Interoperability in ERP systems

\begin{tabular}{|l|l|l|}
\hline Scope & System & Interaction \\
\hline $\begin{array}{l}\text { Internal } \\
\text { (intra-application) }\end{array}$ & ERP Application & ERP Modules \\
\hline $\begin{array}{l}\text { Internal } \\
\text { (intra-organisational) }\end{array}$ & Enterprise system & $\begin{array}{l}\text { ERP and legacy } \\
\text { systems }\end{array}$ \\
\hline $\begin{array}{l}\text { External } \\
\text { (inter-organisational) }\end{array}$ & $\begin{array}{l}\text { Enterprise system } \\
\text { network }\end{array}$ & $\begin{array}{l}\text { ERP and external } \\
\text { enterprise systems }\end{array}$ \\
\hline
\end{tabular}


Table 4. Proposals in the ERP field driven by interoperability.

\section{Themes References}

\section{Technological proposals}

Web Services and SOA

(Chen et al. 2007); (Hofmann 2008);(Yeung 2011);

(Vijay 2011); (Li and Lu 2010); (Vernadat

2007);(Atzori et al. 2010) ; (He and Xu, 2012)

Semantic Web and ontologies

(Izza et al. 2008);(Jagdev et al. 2008); (Grubic

2010); (Paredes-Moreno et al. 2010);(Garcia-Crespo

et al. 2011);(Cardoso and Bussler 2011) ; (Liu et al.

2011)

\begin{tabular}{|ll|}
\hline Enterprise Services Architectures & (Woods and Mattern 2006) \\
\hline EERP & (Li and Zhou 2008); (Xu, 2011) \\
\hline GridERP & (Wang et al. 2008);(Xu 2011) \\
\hline Federated ERP & (Brehm and Marx 2010) (Asfoura et al. 2011) \\
\hline Cloud Computing and SaaS & (AMR 2005); (Sun et al. 2007); (Hofmann 2008); \\
& (Hofmann and Woods 2010);(Elvesæter et al. \\
& 2010);(Jun and Wei 2011), (Narasimhan and \\
& Nichols 2011); (De Maria et al. 2011) \\
\hline Mobile ICT and Internet of Things & (Koh et al. 2006);(Haller et al. 2009);(Soroor \\
& 2009);(Guinard et al. 2009);(Martinez-Sala et al. \\
& 2009);(Kong et al. 2009);(Atzori et al. 2010) \\
\hline Business proposals & (Chen et al. 2008);(Douglas and Strutton 2009); \\
\hline General & (Peng and Nunes 2009) \\
& (Moon 2007);(Huang et al. 2008);(Tewoldeberhan \\
& and Janssen 2008);(Samaranayake \\
& 2009);(Koppenhagen and Maedche 2010);(Dörner \\
BPM and BPR & et al. 2011) \\
\hline Reference models & (Urdaneta et al. 2007);(Panetto 2008);(Blanc et al. \\
& 2008);(Iung et al. 2009) \\
\hline Maintenance & (Gunasekaran and Ngai 2004);(An et al. 2008) \\
\hline Digital Enterprises & (Grefen et al. 2009);(Sun et al. \\
& \\
& \\
&
\end{tabular}




\begin{tabular}{|ll|}
\hline & and Trienekens 2010) \\
\hline PLM & (Chiang 2007);(Newman and Nassehi 2007);(Babič \\
& et al. 2010);(Gulledge et al. 2010);(Marchetta et al. \\
& 2011);(Vijay 2011) \\
\hline Supply Chain & (Koh et al. 2006);(Lo 2008);(Cândido et al. \\
& 2009),(Verissimo 2009);(Coronado et al. \\
& 2009);(Cheng 2010);(Verdouw 2010) \\
\hline Decision Support (DS) and Business & (Botta-Genoulaz et al. 2005); (Smaizys and \\
Intelligence(BI) & Vasilecas 2009); (Collins and Sadeh 2009); (Liu \\
& and Liu 2010); (Forslund 2010) \\
\hline
\end{tabular}


Figure 1. Interoperability Reference Model (Adapted from Gathner, 2007)

Figure 2. Influences on ERP systems

Figure 3. New generation of interoperable ERP systems 